\title{
Preparation of High Photoluminescent Hybrid Polymer-CdS Nanoparticle with Chelating Functional Polymer
}

\author{
Cheng-Chien Wang, ${ }^{1,2}$ An-Liu Chen, ${ }^{1}$ and I-Han Chen ${ }^{1}$
}

ERRATUM TO: JOURNAL OF INORGANIC

AND ORGANOMETALLIC POLYMERS AND

MATERIALS DOI: 10.1007/s10904-006-9033-z

The submitted and accepted dates for this paper were inadvertently omitted. The dates are as follows:

Submitted August 24, 2005; accepted September 28, 2005

\footnotetext{
The online version of the original article can be found at http:/ dx.doi.org/10.1007/s10904-006-9033-z

${ }^{1}$ Department of Chemical and Material Engineering, Southern Taiwan University of Technology, Tainan, 710, Taiwan.

2 To whom correspondence should be addressed.

E-mail: ccwang@mail.stut.edu.tw
} 